Document downloaded from:

http://hdl.handle.net/10251/45546

This paper must be cited as:

Caro Forero, LA.; Martí Vargas, JR.; Serna Ros, P. (2013). Prestress losses evaluation in prestressed concrete prismatic specimens. Engineering Structures. 48:704-715. doi:10.1016/j.engstruct.2012.11.038.

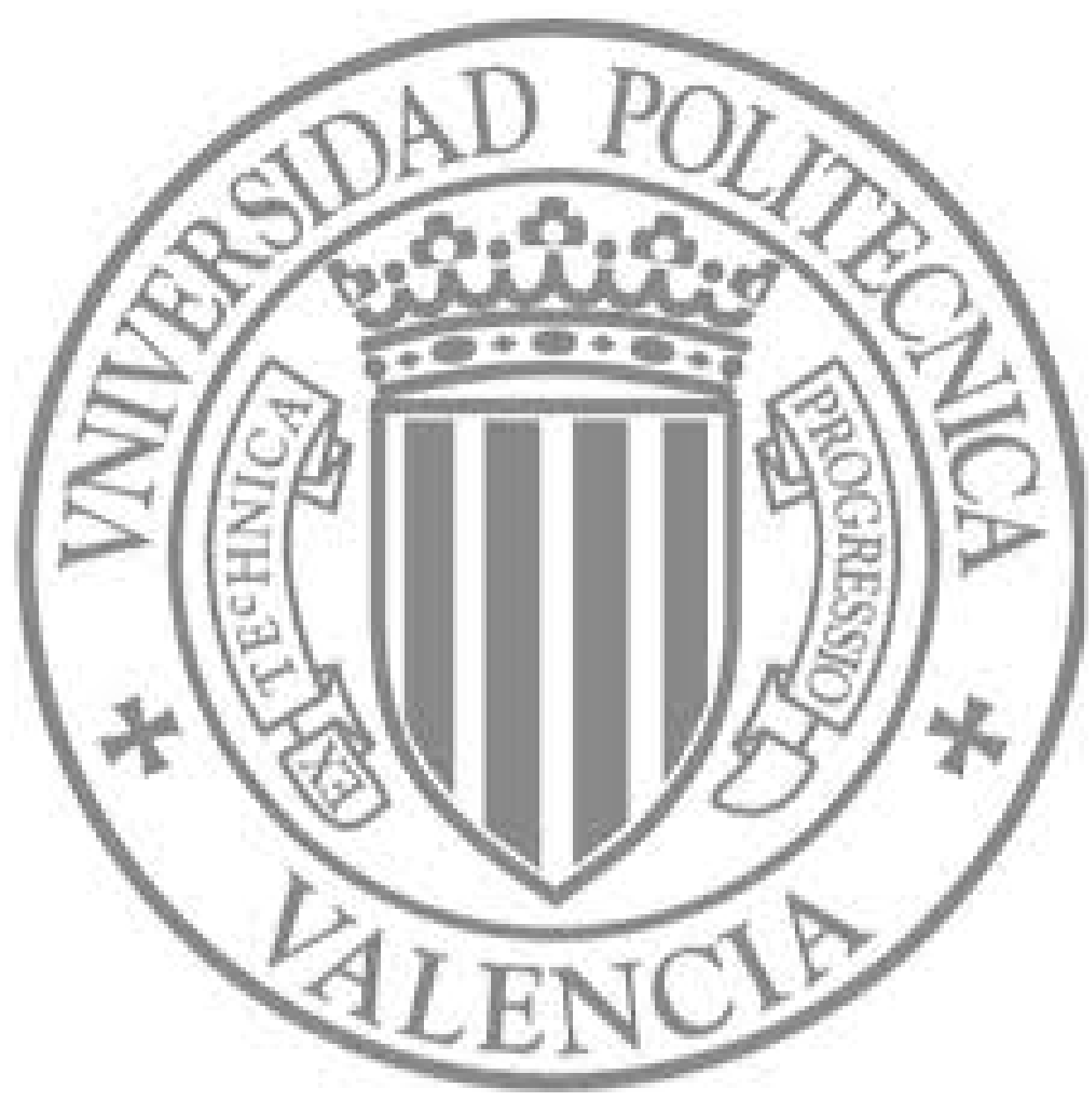

The final publication is available at

http://dx.doi.org/10.1016/j.engstruct.2012.11.038

Copyright Elsevier 


\section{Prestress losses evaluation in prestressed concrete prismatic specimens}

2

3
L.A. Caro, J.R. Martí-Vargas*, P. Serna

Institute of Concrete Science and Technology (ICITECH)

Universitat Politècnica de València, 4G, Camino de Vera s/n, 46022, Valencia, Spain

e-mail address:

licafo@doctor.upv.es; jrmarti@cst.upv.es; pserna@,cst.upv.es;

*Corresponding author: Tel.: +34 963877007 (ext. 75612); Fax: +34 96 3877569;

e-mail address: jrmarti@cst.upv.es (José R. Martí-Vargas)

\section{Abstract}

This paper presents an experimental research work to evaluate prestress losses in pretensioned prestressed concrete. An experimental program including variables such as concrete mix design, specimen cross-section size and concrete age at the prestress transfer was carried out. Several pretensioned prestressed concrete prismatic specimens were made and tested using the ECADA+ test method, based on measuring prestressing reinforcement force. In addition, specimens were instrumented to obtain the longitudinal concrete strains profiles at any time. Measurements from both techniques were taken over one year. Measured prestress losses included elastic shortening losses and time-dependent losses due to concrete shrinkage and creep. A coefficient to account for the relationship between the prestress losses from the measured prestressing forces and the actual prestress losses from concrete compressive strains is proposed. The experimental results were compared with the predicted prestress losses using methods from several codes.

\section{Keywords}

Concrete, pretensioned, prestress loss, creep, shrinkage, transfer, strain 


\section{Introduction}

3 There are two procedures for prestressing a concrete member through reinforcement: post4 tensioning and pre-tensioning. In both cases, the initial tensile stress applied in the 5 prestressing reinforcement decreases through several sources. The difference between initial 6 tensile stress and tensile stress in prestressing reinforcement at any time $t$ is defined as total 7 prestress loss $\left(T P L_{t}\right)$. Usually, $T P L_{t}$ is quantified as a percentage over initial tensile stress.

9 It is generally accepted that prestress losses have little effect on ultimate design strength and on the capacity of pretensioned concrete members, but that prestress losses can affect service conditions [1]. Upon service loads, overestimating prestress losses can lead to excessive camber and inefficient designs, while underestimating prestress losses can result in excessive deflection and unexpected cracks.

Prestress losses can be determined analytically and experimentally. Methods to estimate prestress losses can be classified into the following levels, listed in ascending order in terms of complexity and accuracy [2-3]: I) lump-sum or approximate methods to estimate $T P L$ (oversimplified methods for preliminary design): II) refined or detailed methods to estimate prestress losses separately due to each particular source (commonly used for designs based on elemental information about materials properties and environmental conditions); and III) accurate determination of cumulative losses by time-step methods, which involves knowledge of the loading history on the member (useful in multi-stage bridge constructions at any critical time). 
1 The experimental techniques used to determine prestress losses include several typologies [4-

2 7]: 1) monitoring longitudinal concrete strains over time at the level of the center of gravity of

3 the prestressing reinforcement; 2) load testing to determine crack initiation and/or crack re-

4 opening loads to obtain the available compressive stress in the bottom flange of a member; 3 )

5 severing the prestressing reinforcement by cutting it into a representative exposed length after

6 placing strain gauges on the reinforcement; 4) relating the tension in the prestressing

7 reinforcement to the vertical deflection recorded when known weights are suspended from it on a representative exposed length; and 5) determining the side pressure to close the induced crack in a small cylindrical hole drilled in the bottom flange of a member.

All these experimental techniques require a back-calculation of the prestress losses from the test data using theory of mechanics concepts. Method 1 requires the instrumentation of the member during casting, and it can be used to determine prestress losses over time. Methods 2 and 3 are destructive tests and provide information only on the existing prestressing reinforcement stress at testing times (prestress losses are frequently obtained by considering 16 theoretical rather than measured initial prestressing reinforcement stress). Method 4 is a 17 semidestructive test and involves accurately determining the exposed length for calculations. Method 5 is a non-destructive technique which involves an appropriate factor by numerical procedures.

21 The main objective of this experimental research work is to analyze changes in prestress 22 losses over time in pretensioned prestressed concrete using a testing technique that allows the simultaneous application of the aforementioned Method 1 and the continuous measurement of prestressing reinforcement force. To this end, an experimental program has been set up over a 1 -year period with several pretensioned prestressed concrete prismatic specimens varying in 
1 terms of concrete mix design, specimen cross-section size, and concrete age at the prestress

2 transfer. The ECADA+ test method [8] has been used to measure the effective prestressing

3 force over time. In addition, specimens have been instrumented to determine the longitudinal

4 concrete surface strain by mechanical gauge points. The experimental results have been

5 compared with predicted prestress losses from existing methods in several codes.

\section{Background}

\subsection{Sources of prestress losses}

For pretensioned prestressed concrete members, the manufacturing process involves the following main stages:

a) First the prestressing reinforcement is tensioned in the casting bed by stretching it between abutments using provisional end anchorages. Instantaneous anchorage seating elastic loss occurs (prestress loss ranging from $f_{p, j a c k}$-initial at jacking- to $f_{p, b e d}$-at anchoring-). This prestress loss can be determined from the equipment and fabrication system characteristics, and very often they are fully or partially compensated for by overjacking.

b) Next, while relaxation loss of the prestressing reinforcement occurs, the concrete member is cast around the prestressing reinforcement and additional factors such as temperature by the curing method increases relaxation prestress loss (prestress losses ranging from $f_{p, b e d}$ to $f_{p 0}$-just before the prestress transfer-).

c) Finally, when sufficient strength is attained by the concrete, the provisional end anchorages are released and the prestressing reinforcement tends to shorten. The concrete around the prestressing reinforcement shortens as the prestressing force is applied to it, as the 
1 due to the elastic shortening of concrete occur in the central zone of the member (prestress

2 losses ranging from $f_{p 0}$ to $f_{p i}$-initial effective stress, just after the prestress transfer-), and

3 special end zones by varying the prestressing reinforcement stress from zero at the free ends of the member to $f_{p i}$ necessarily exist. The length of these end zones is defined as transfer length [1].

7 As time passes after the prestress transfer, several time-dependent prestress losses gradually occur by the following sources: concrete shrinkage -volumetric decrease in concrete mass-; concrete creep -increase in compressive strains under sustained stress-; and prestressing reinforcement relaxation -lowered tensile stress under sustained elongation- (as the

11 prestressing reinforcement shortens by concrete shrinkage and creep, a less marked relaxation 12 loss rather than intrinsic relaxation -for constant length and temperature- takes place).

Consecuently, effective stress will change from $f_{p i}$ to a final value $f_{p e}$ after allowing for all the prestress losses. At any time $t$, effective stress will be $f_{p t}$, and $T P L_{t}$ can be expressed as 16 follows:

$$
T P L_{t}=\frac{f_{p, j a c k}-f_{p t}}{f_{p, j a c k}}(\text { in \% })
$$

Accordingly with [9], $T P L_{t}$ ranges from $20 \%$ to $35 \%$. The contribution of each prestress loss source to $T P L_{t}$ depends on the structural design, the manufacturing process, materials properties, environmental conditions during service life and the time elapsed.

Eq. (1) is of interest for precasters, but $f_{p, j a c k}$ never acts on concrete; therefore, other expressions can be used by replacing $f_{p, j a c k}$ with $f_{p 0}$ or $f_{p i}$ in Eq. (1) to obtain expressions of 25 primary interest for designers to account for only the part of $T P L$ that is of practical 
1 significance. The available tensile stress to be applied to concrete by the prestressing

2 reinforcement is $f_{p 0}$, which is reduced to $f_{p i}$ immediately after the prestress transfer and to $f_{p e}$

3 after all losses have occurred. Effectiveness ratios can be defined for any time $t$, and

4 particulary in the long term [10]:

5

$$
R_{0 t}=\frac{f_{p t}}{f_{p 0}}
$$

7

$$
R=\frac{f_{p e}}{f_{p i}}
$$

$$
R_{i t}=\frac{f_{p t}}{f_{p i}}
$$

\section{$11 \quad 2.2$ Previous research on prestress losses}

12 concrete girders, which exceeded the allowable compressive stress limit [12].

Numerous studies have been conducted in the past to measure prestress losses in pretensioned prestressed concrete members and to compare these losses versus design code estimations. Among these studies, there are several laboratory tests of old girders removed from existing bridges and experimental research works including fabrication, testing and field monitoring of pretensioned concrete members under service. Table 1 in [5] and Table 6 in [11] summarize an extensive literature review on references, pretensioned prestressed concrete member identification (type, old time), testing place, experimental technique used, time of study and measured losses. As observed in these tables, measured prestress losses exceed the losses predicted by code specifications in some cases. On the other hand, measured prestress losses that are in line with the values expected by current codes have been obtained in prestressed 
1 Besides, several studies have been conducted on computational analyses of prestress losses

$2[2,13]$ and on probabilistic assessments $[14,15]$.

\subsection{Methods for estimating prestress losses}

6 Determination of prestress losses usually involves complicated, laborious procedures because 7 time-dependent prestress losses are inter-dependent [16]. Prestressing reinforcement 8 relaxation is continuously altered by changes in stress due to concrete shrinkage and creep.

9 Concrete creep, in turn, constantly alters by changes in prestressing reinforcement stress. 10 Moreover, concrete shrinkage and creep movements are partially restrained by the 11 prestressing reinforcement.

13 As time-dependent prestress losses are performed gradually, a concrete creep at any time $t$ is 14 less than a creep due to the same prestress loss if applied at its full value at the initial time. This phenomenon is frequently accounted for by means of an aging coefficient smaller than 16 unity, which can be included in an age-adjusted effective elasticity modulus of concrete $17 \quad[17,18]$.

Several methods and empirical equations which use the aging coefficient or are based on simplified analyses are available in the current codes that predict prestress losses.

According to ACI 318 Commentary [1] and PCI DH [19], reasonably accurate prestress losses estimations can be calculated in accordance with the recommendations established by Zia et al. [20]. For unusual design conditions and special structures, a more detailed procedure established by PCI CPL [21] can be considered. 
2 More recently, AASHTO LRFD [22] adopted new methods (approximate and refined-detailed

3 methods based on [3,11]) in 2007 to estimate prestress losses since the current prestress losss

4 methods led to unrealistic applications with high-strength concrete. However, AASHTO

5 Standard [23] specifications for prestress losses estimation remain in accordance with 2004

6 AASHTO LRFD [24]. PCI BDM [25] includes both the AASHTO Standard [23] and the

7 LRFD [24] methods.

9 The Spanish Code specifications of structural concrete [26] for prestress losses estimations account for the aging coefficient, and they coincide with the specifications established in both 11 Eurocode-2 [27] and Model Code 2010 [18].

12

\section{Testing technique}

The ECADA+ test method [8] has been used. ECADA+ is a revised, improved version of the original ECADA ${ }^{1}$ test method [28], and it determines transfer length and development length $[29,30]$. Its feasibility has been verified for short-term [31,32] and long-term [33] analyses.

In this work, only specimens with an embedment length longer than the transfer length have been included in the experimental program. Hence in this case, the ECADA+ test method [8] has been used to measure effective prestressing force over time and, complementarily, specimens have been instrumented to determine longitudinal concrete surface strains.

\subsection{Test basis, equipment and instrumentation}

\footnotetext{
1 ECADA is the Spanish acronym for "Ensayo para Caracterizar la Adherencia mediante Destesado y Arrancamiento"; in English: "Test to Characterize Bond by Release and Pull-out"
} 
2 The ECADA+ test method is based on measuring and analysing the force supported by the 3 prestressing reinforcement in a series of pretensioned prestressed concrete specimens with 4 different embedment lengths over time. Specimens were made and tested using pretensioning 5 frames, as shown in Fig. 1. In this way, each specimen has only one special end zone with the 6 corresponding transfer length.

8 A hollow hydraulic actuator with an end-adjustable anchorage device was placed at one end

9 of the pretensioning frame (see Fig. 1) to carry out operations of tensioning, provisional 10 anchorage, and detensioning of prestressing reinforcement. At the opposite end, an 11 Anchorage-Measurement-Access (AMA) system was placed to simulate specimens' sectional 12 rigidity.

14 The strictly necessary instrumentation devices for the ECADA+ test method include a 15 pressure transducer to control the hydraulic actuator, and a hollow force transducer placed in 16 the AMA system to measure prestressing reinforcement forces at all times during the test 17 (tensioning, provisional anchorage, detensioning, and analysis with time). A hollow force transducer HBM C6A was used in each specimen test. Additionally, detachable mechanical strain gauges (DEMEC points) were used to obtain the

21 longitudinal concrete surface strains at the prestressing reinforcement level. An extensometer 22 was used to measure the distance between gauge points with a $100 \mathrm{~mm}$ gauge length. Gauge points were spaced at $50 \mathrm{~mm}$ intervals. 
1 No internal measuring devices were used in the tested specimens to not distort the bond 2 phenomenon.

\subsection{Specimen preparation and fabrication}

6 Specimen preparation and fabrication followed these phases:

$7 \quad$ Lining up the prestressing reinforcement in the pretensioning frame with both anchorage 8 devices at their ends.

9 - Prestressing reinforcement tensioning using the hydraulic actuator (Fig. 2a).

10 - Acting on the prestressing reinforcement to avoid relaxation losses ${ }^{2}$.

11 - Provisional prestressing reinforcement anchorage by unscrewing the end-adjustable 12 anchorage to mechanically block the hydraulic actuator (Fig. 2b).

13 - Specimen concreting into the integrated mould, mounted in the pretensioning frame, 14 around the prestressing reinforcement.

15 - Maintaining the selected conservation conditions to achieve the desired concrete 16 properties.

$17-$ Demounting the mould from the pretensioning frame.

18 - Attaching gauge points by epoxy glue along both lateral sides of the specimen at the 19 prestressing reinforcement level (Fig. 2c).

\section{$21 \quad 3.3$ Test procedure}

23 The different test procedure phases were the following:

24 a) Prestress transfer release:

\footnotetext{
${ }^{2}$ By following the manufacturer's recommendations, the prestressing reinforcement was overtensioned at $82 \%$ of the nominal ultimate reinforcement strength over a 10 -minute period prior to anchoring.
} 
1 - Reading the initial set of distances between gauge points (before the prestress transfer).

2 - Releasing the provisional anchorage: the hydraulic actuator recovered the actual 3 prestressing reinforcement force $\left(P_{0}\right)$, and the end-adjustable anchorage was relieved and $4 \quad$ withdrawn by screwing (Fig. 2d).

5 - Detensioning: the hydraulic actuator was unloaded in a controlled manner, and the

6 prestressing reinforcement movement from the free end was produced by push-in. When

7 the prestressing reinforcement had been completely released, the prestressed specimen was

$8 \quad$ supported by the AMA system.

$9 \quad$ - Stabilization period.

$10 \bullet$ Measuring the prestressing reinforcement force achieved $\left(P_{t 1}\right)$ in the AMA system.

11 - Re-reading the set of distances between gauge points (after the prestress transfer).

12 b) Prestressed specimen storage:

13 - Demounting the pretensioned prestressed concrete specimen joined to the AMA system 14 from the pretensioning frame (Fig. 2f).

15 - Storing the demounted specimen under controlled conservation conditions.

16 - Subsequent measurement of the prestressing reinforcement force $\left(P_{t}\right)$ in the AMA system 17 and reading the set of distances between gauge points at a given time was done 18 periodically.

\subsection{Results}

22 An approximate transfer length determination can be obtained from the longitudinal concrete surface strains [34]. These strains can be obtained from the changes of distances between gauge points before and after the prestress transfer. The strain change for each 100 gauge length is assigned to its center point sequentially from the free end. A bilinear profile with an 
1 ascendent initial branch and a practically horizontal branch at which the concrete surface

2 strains became somewhat uniform was observed when these longitudinal concrete strains

3 were plotted according to specimen embedment length. Transfer length can be estimated as

4 the length of the first region; that is, as the distance from the free end marking the beginning

5 of the horizontal branch (Fig. 3).

7 Beyond transfer length, the constant strain plateau corresponds to the region of the specimen where compatibility of strains between the prestressing reinforcement and the concrete exists.

9 Prestress losses can be determined in this region, and transfer length remains as a special end region where prestress losses occur in addition to the bond phenomenon.

12 The effective prestressing force at any time $t$ can be measured from the AMA system and can 13 be also obtained from the concrete compressive strains in the region plateau of the specimens 14 according to Eq. (6) based on strains compatibility between concrete and the prestressing 15 reinforcement $\left(\Delta \varepsilon_{c}=\Delta \varepsilon_{p}\right)$ :

16

$$
P_{t, s}=P_{0}-T P L_{t, s}=P_{0}-\Delta \varepsilon_{p}(t) \cdot E_{p} \cdot A_{p}
$$

17 where:

$18 P_{t, s}$ is the effective prestressing reinforcement force at time $t$ from specimen strains

$19 P_{0}$ is the prestressing reinforcement force just before the prestress transfer

$T P L_{t, s}$ is the total prestress loss accounted for until time $t\left(T P L_{t, s}=\Delta \varepsilon_{p}(t) \cdot E_{p} \cdot A_{p}\right)$

$21 \Delta \varepsilon_{p}(t)$ is the prestressing reinforcement strain change beyond transfer length, accounted for 22 from just before the prestress transfer until time $t$

$23 E_{p}$ is the elasticity modulus of the prestressing reinforcement

$24 A_{p}$ is the prestressing reinforcement area 
1 From the initial longitudinal concrete strains profile $\left(\varepsilon_{t l}\right)$, the initial effective prestressing

2 force $\left(P_{t 1, s}\right)$, including prestress losses due to the elastic shortening of concrete, can be

3 obtained. From subsequent profiles $\left(\varepsilon_{t}\right)$ at any time $t, P_{t, s}$ and accumulated prestress losses can

4 be obtained.

5

6 Furthermore, the ideal AMA system must have the same sectional rigidity as the specimen

7 and must display the same time-dependent behavior $[8,28]$. Sectional rigidity depends on the

8 concrete properties and the specimen's cross-section. For different test conditions, various

9 AMA system designs should be devised. However, it is not really feasible to design a system

10 for each specific test condition. For this reason, the rigidity of the AMA system design is

11 greater than the specimens' sectional rigidity (it must never be lower), and the prestressing

12 reinforcement force measured in the AMA system after release is greater than the effective

13 prestressing force in the specimen, resulting in an end-discontinuity effect (Fig. 4).

14

154 Experimental program

16

17 To study the prestress losses changes over a 1-year period on several pretensioned concrete

18 prismatic specimens, an experimental program was carried out by varying the concrete mix

19 design, specimen cross-section size and concrete age at the prestress transfer.

\section{$21 \quad 4.1$ Materials}

23 Three different concrete mix designs applicable for the precast prestressed concrete members

24 industry with different compressive strengths at the time of testing $\left(f^{\prime}{ }_{c i}\right)$ ranging from 24 to 58

$25 \mathrm{MPa}$ were tested. For all the concretes, the components were: cement CEM I $52.5 \mathrm{R}$ [35], 
1 crushed limestone aggregate $(7-12 \mathrm{~mm})$, washed rolled limestone sand $(0-4 \mathrm{~mm})$, and a

2 superplasticizer additive. The mix design and concrete compressive strength of the tested 3 concretes are shown in Table 1.

The prestressing reinforcement was a low-relaxation seven-wire steel strand specified as UNE 36094:97 Y 1860 S7 13.0 [36] with a guaranteed ultimate strength of $1860 \mathrm{MPa}$. The main characteristics were adopted from the manufacturer: $13 \mathrm{~mm}$ diameter, a cross-sectional area of

$8100 \mathrm{~mm}^{2}$, ultimate strength of $200.3 \mathrm{kN}$, yield stress at $0.2 \% 189.9 \mathrm{kN}$, and an elasticity modulus of 203.35 GPa. The prestressing strand was used under the as-received condition. Strands were rust- and lubricant-free, without any special treatment.

\subsection{Specified parameters}

All the specimens were prestressed by means of a concentrically located single strand at the prestress level before releasing $75 \%$ of the nominal ultimate strand strength. Specimen 16 embedment length was always ${ }^{3} 1350 \mathrm{~mm}$, and three different cross-sections were used: $100 \times 100 \mathrm{~mm}^{2}, 80 \times 80 \mathrm{~mm}^{2}$, and $60 \times 60 \mathrm{~mm}^{2}$. All the specimens were subjected to the same consolidation and curing conditions.

The prestress transfer release time was specified for each specimen. The prestress transfer was 21 gradually performed at a controlled speed of $0.80 \mathrm{kN} / \mathrm{s}$. A stabilization period of 2 hours from 22 the release was established for the initial analysis of the test results.

\footnotetext{
3 Based on previous studies by the authors [29-33] and on analytical predictions from equations in the literature $[37,38], 1350 \mathrm{~mm}$ is longer than the transfer length for the specified parameters.
} 
1 Specimens were stored inside a chamber where temperature and humidity were controlled:

2 temperature, $20-22^{\circ} \mathrm{C}$; relative humidity, $50-60 \%$. Fig. 5 shows some instrumented specimens

3 with the corresponding AMA system in the chamber. After storage, subsequent sets of gauge

4 points readings and prestressing reinforcement force measurements were taken at 1, 2, 3, 7, $5 \quad 14$, and 28 days, and then monthly.

6

7

8

9

\section{Test results and discussion}

\subsection{Program} controlled storage chamber size. the prestress transfer $(12,24$ or $48 \mathrm{~h})$. shrinkage measurements.

The three different cross-sections used were combined with the three concrete mix designs. Besides, several ages of prestress transfer release were established. Table 2 summarizes the test program established. It was not possible to test all the combinations because of the

A specimen designation is: M-D-T, where $\mathrm{M}$ is the concrete mix type (A, B, or C), D is the side (in $\mathrm{mm}$ ) of the specimen cross-section $(100,80$ or $60 \mathrm{~mm})$, and $\mathrm{T}$ is age in hours $(\mathrm{h})$ at

In addition, non-pretensioned concrete specimens were made for each concrete mix design to measure concrete shrinkage in specimens with and without untensioned prestressing reinforcement. These specimens were instrumented with DEMEC points and were stored under the same conditions in the chamber. Fig. 6 offers a view of some specimens for the 


\section{$1 \quad 5.1$ Experimental measurements}

3 For this work, the prestress losses accounted for between jacking and the prestress transfer

4 release were excluded. As the hollow force transducer was placed in the AMA system in 5 contact with the anchorage device, the prestressing reinforcement force just before the 6 prestress transfer release $\left(P_{0}\right)$ was known. Furthermore, prestress losses due to prestressing $3.2)$.

By way of example, Fig. 7 shows the longitudinal concrete strains profiles at several ages for specimen A-100-24. The results were obtained by averaging the readings from two opposite specimen faces. The three zones observed were: transfer length, plateau, and enddiscontinuity. Greater concrete compressive strains resulted from early concrete age at the prestress transfer. Transfer length was $400 \mathrm{~mm}$. The initial end-discontinuity zone was approximately $200 \mathrm{~mm}$ in length given the sequence of readings from the DEMEC points: there was a $120-\mathrm{mm}$ sleeve beyond the $1350-\mathrm{mm}$ specimen embedment length, and the first affected readings were the $100-\mathrm{mm}$ gauge length corresponding to the $1250-1350 \mathrm{~mm}$ embedment length, whose values were assigned to its center point $-1300 \mathrm{~mm}$-. As time passed, end-discontinuity became more pronounced because of the different time-dependent behaviors displayed by the AMA system in relation to the specimen.

Table 3 summarizes the main test results just after the prestress transfer and after one year, including the measured prestressing reinforcement forces in the AMA system $\left(P_{0}, P_{t l}, P_{t}\right)$, the average concrete strains for the plateau zone $\left(\varepsilon_{t l}, \varepsilon_{t}\right)$ and the corresponding effective prestressing forces $\left(P_{t 1, s}, P_{t, s}\right)$ according to Eq. (6). Specimens were ordered according to 
1 concrete mix design by increasing both cross-section size and concrete age at the prestress

2 transfer.

4 As observed in Table 3, an overestimation of the prestressing reinforcement force was

5 obtained when measuring prestressing forces was considered: $P_{t l}$ and $P_{t}$ were always greater

6 than $P_{t l, s}$ and $P_{t, s}$, respectively. This was caused by the end-discontinuity effect and,

7 consequently, the actual prestress losses were underestimated from measuring prestressing

8 forces. In order to determine appropriate coefficients to account for prestress losses

9 underestimation, several adjustments based on specimen cross-section sizes were made for

10 both the instantaneous and time-dependent responses of the AMA system; see Fig. 8.

11 Therefore, the following equation is proposed:

12

$\Delta P=\kappa \cdot \Delta P_{A M A}$

13 where:

$14 \Delta P$ is the actual prestress losses (from the specimen strains)

$15 \kappa$ is a coefficent to account for the end-discontinuity effect

16 for the instantaneous response:

2.2 (for 100x100 $\mathrm{mm}^{2}$ specimen cross-section), $2.4\left(80 \times 80 \mathrm{~mm}^{2}\right)$, and $2.8\left(60 \times 60 \mathrm{~mm}^{2}\right)$

18 for the time-dependent response:

2.8 (for 100x100 $\mathrm{mm}^{2}$ specimen cross-section), $2.6\left(80 \times 80 \mathrm{~mm}^{2}\right)$, and $2.4\left(60 \times 60 \mathrm{~mm}^{2}\right)$

$\triangle P_{A M A}$ is the prestress losses from the measured prestressing forces

Fig. 9 depicts both the instantaneous and time-dependent prestress losses for all the specimens tested, including the prestress losses from specimen strains, the prestress losses from the measured prestressing forces, and the adjusted values of the prestress losses according to Eq.

25 (7). As observed, the actual prestress losses can be estimated from the measured prestressing 
1 forces by applying the obtained $\kappa$ coefficient. The tendencies according to concrete mix

2 design, specimen cross-section size, and concrete age at the prestress transfer were maintained

3 with the estimation, and only a few values offered a relatively poor estimation.

5 In order to separately obtain time-dependent losses by concrete creep and shrinkage, Fig. 10

6 depicts the average concrete strains for the plateau zone with the time for specimen A-100-24

7 by way of example. The upper curve, obtained from the longitudinal concrete strains profiles

8 at each time, accounts for the total concrete strains (instantaneous -just after prestress

9 transfer, time $0-$ and time-dependent). Besides, the lower curve, obtained from the

10 longitudinal concrete strains measured in non-pretensioned concrete specimens with

11 untensioned prestressing reinforcement to determine concrete shrinkage, was included. By

12 substracting measured shrinkage strains from measured total strains, the concrete strains

13 under loading at each time are obtained. Now, by substracting measured instantaneous strains

14 from concrete strains under loading, strains due to concrete creep at each time can be

15 determited. Therefore, the prestress losses due to concrete creep can be accounted for

16 separately by the other sources.

17

Fig. 11 shows the prestress losses obtained experimentally by the three sources (elastic shortening, creep and shrinkage) for all the specimens tested. As this figure illustrates, prestress losses decrease in a same concrete mix design when the specimen cross-section increases and the concrete age at the prestress transfer increases. For equal specimen crosssection size and concrete age at the prestress transfer, the prestress losses in specimens made with concrete $\mathrm{C}$ are greater than those in specimens made with concrete $\mathrm{B}$ which, in turn, are greater than the prestress losses in specimens made with concrete A: C-100-48/B-100-48; C100-24/B-100-24/A-100-24; C-80-48/B-80-48; B-80-24/A-80-24; B-60-48/A-60-48. Larger 
1 differences between specimens correspond to the prestress losses due to concrete elastic

2 shortening, whose values ranged from $10 \%$ for the specimens with greater cross-sections, 15 -

$320 \%$ for specimens with intermediate cross-sections, and $25-30 \%$ for specimens with smaller

4 cross-sections. The total measured prestress losses values ranged from $25-60 \%(25-40 \%$ for

5 specimens with greater cross-sections, $40-50 \%$ for specimens with intermediate cross-

6 sections, and $50-60 \%$ for those with smaller cross-sections), exceeding the percentages

7 detailed for design according to [9], except for those specimens with greater cross-sections.

8 This fact can be explained by the different concrete stress levels and the deformability

9 behavior relating to specimen cross-sections.

5.2 Comparison with predicted prestress losses

12

13 Theoretical values of prestress losses were estimated by measuring parameters using several 14 prestress loss methods for comparison purposes: PCI DH [19], PCI CPL [21], AASHTO STD [23], AASHTO LRFD [22] (Approximate and Refined methods), and MC [18] - EC [27] EHE [26]. By way of example, Fig. 12 depicts the measured and predicted prestress losses for specimen A-100-24.

As observed in Fig. 12, prestress losses due to elastic shortening practically did not differ among the various methods. The best prediction for total prestress losses corresponded to the AASHTO LRFD Refined, in spite of an overestimation of prestress losses due to concrete creep and an underestimation of prestress losses due to concrete shrinkage. The MC/EC2/EHE method well predicted prestress losses due to concrete creep, and it also gave the greater prestress loss prediction due to concrete shrinkage. The most simplified methods 
1 (PCI DH, AASHTO STD, AASHTO LRFD Approximate) gave similar prestress losses due to concrete shrinkage, but differed in their predictions of prestress losses due to concrete creep.

4 The prestress losses predicted by all the aforementioned methods for all the specimens were computed and are summarized in Table 4. The comparisons made of the predicted prestress

6 losses with measured prestress losses are included in Figs. 13, 14 and 15, which depict the total prestress losses after one year, the predicted/measured ratios, and the effectiveness ratios according to Eq. (4), respectively.

As observed in Fig. 13, the tendencies of the measured prestress losses according to the variables concrete mix design, specimen cross-section size and concrete age at the prestress transfer are followed by the predicted prestress losses by all the methods: for all the methods, total prestress losses lowered within the same concrete mix design when the specimen crosssection increased and the concrete age at the prestress transfer increased, and predicted prestress losses in those specimens made with concrete $\mathrm{C}$ were greater than the prestress losses in those made with concrete B, and they were also greater than prestress losses in specimens made with concrete A.

As Fig. 14 illustrates, the AASHTO LRFD Refined and the MC/EC2/EHE methods show the best predictions. Some slow trends to underestimate both the prestress losses for concrete mix design $\mathrm{C}$ from the AASHTO LRFD Refined method and the prestress losses for concrete mix design A from the MC/EC2/EHE method are depicted. PCI DH, PCI CPL, and the AASHTO STD methods gave similar predictions, with slow trends to a greater underestimation of prestress losses when concrete compressive strength decreases (within the same concrete mix design, and for different concrete mix designs maintaining specimen cross-section and 
1 concrete age at the prestress transfer). The AASHTO LRFD Approximate method shows the

2 best agreement with the AASHTO LRFD Refined method when concrete compressive 3 strength decreased.

5 Finally, Fig. 15 shows the effectiveness ratios obtained by Eq. (4) from the measured values

6 and by all the methods. After one year, the tensile stress available in the prestressing 7 reinforcement ranged with values from 0.55 to 0.80 times the prestressing reinforcement 8 stress immediately after the prestress transfer. For the different variables considered in the test

9 program, higher ratios were recorded for those cases with greater concrete compressive 10 strength, larger specimen cross-section size, and higher concrete age at the prestress transfer.

11 In Fig. 15, the global trends depending on prediction methods are depicted consistently with 12 the trends observed in Figs. 13 and 14.

\section{Conclusions}

16 Changes in prestress losses over one year in pretensioned prestressed concrete specimens

17 have been analyzed by simultaneously using two measurement techniques: prestressing reinforcement force measurement through the ECADA+ test method; longitudinal concrete

19 strains measurement at the level of the center of gravity of the prestressing reinforcement. The 20 main conclusions drawn from this experimental study are:

21 - A prestress losses underestimation has been obtained from the measured prestressing 22 reinforcement forces. Based on specimen cross-section size, appropriate coefficients related 23 to the effective prestressing forces from specimen strains to account for prestress losses 24 underestimation have been established for both the instantaneous and time-dependent 25 responses of the equipment test. 
1 - The different concrete stress level and deformability behavior related to the specimens'

2 cross-section influences prestress losses: prestress losses decrease in the same concrete mix

3 design when the specimen cross-section increases and concrete age at the prestress transfer

4 increases; for equal cross-sections and concrete age at the prestress transfer, prestress losses

5 decrease when the specimen's concrete compressive strength increases.

6 - The larger differences between specimens correspond to prestress losses due to elastic

7 shortening of concrete, whose values range from $10 \%$ for specimens with greater cross-

8 sections, $15-20 \%$ for specimens with intermediate cross-sections, and $25-30 \%$ for specimens

$9 \quad$ with smaller cross-sections.

10 The total measured prestress losses values range from $25-60 \%: 25-40 \%$ for specimens with 11 greater cross-sections, $40-50 \%$ for specimens with intermediate cross-sections, and $50-60 \%$

12 for specimens with smaller cross-sections.

13 - The prestress losses predicted by several methods based on codes follow the tendencies seen

14 for measured prestress losses: total prestress losses decrease with greater concrete 15 compressive strength, greater specimen cross-section, and higher concrete age at the 16 prestress transfer.

17 - The AASHTO LRFD Refined and the MC/EC2/EHE methods offer the best predictions. 18 The PCI DH, PCI CPL, and AASHTO STD methods provide similar predictions, with a 19 slow trend towards a more marked prestress losses underestimation when concrete 20 compressive strength decreases. The AASHTO LRFD Approximate method agrees the most 21 with the AASHTO LRFD Refined method when concrete compressive strength decreases.

22 - The prestressing effectiveness ratios range from 0.55 to 0.80 of prestressing reinforcement 23 stress immediately after the prestress transfer. Higher ratios were recorded for cases with 24 greater concrete compressive strength, greater specimen cross-section size and higher 25 concrete age at the prestress transfer. 


\section{Acknowledgments}

4 Funding for this experimental research work has been provided by the Spanish Ministry of

5 Education and Science and ERDF (Project BIA2006-05521 and Project BIA2009-12722).

6 Tests have been conducted at the Institute of Concrete Science and Technology (ICITECH), 7 at the Universitat Politècnica de València (Spain).

\section{References}

10 [1] ACI Committee 318. Building Code Requirements for Reinforced Concrete (ACI 318-11).

11 Farmington Hills, MI: American Concrete Institute; 2011.

12 [2] Naaman AE, Hamza AM. Prestress losses in partially prestressed high strength concrete beams. PCI J 1993;38(3):98-113.

[3] Tadros MK, Al-Omaishi S, Seguirant SJ, Gallt JG. Prestress losses in pretensioned highstrengh concrete bridge girders. NCHRP report $n^{\circ}$ 496. Washington, DC: Transportation Research Board, National Academy of Sciences; 2003. pretensioned concrete box girders. ACI Struct J 1997;94(5):471-482.

[5] Baran E, Shield CK, French CE. A comparison of methods for experimentally determining prestress losses in pretensioned prestressed concrete girders. In: Russell BW, Gross SP,

21 editors. Historic innovations in prestressed concrete. Farmington Hills, MI: American 22 Concrete Institute; 2005, p. 161-179.

[6] Azizinamini A, Keeler BJ, Rohde J, Mehrabi AB. Application of a new nondestructive evaluation technique to a 25-year-old prestressed concrete girder. PCI J 1996;41(3):82-95. 
1 [7] Wu CH, Zhao W, Beck T, Peterman R. Optical sensor developments for measuring the

2 surface strains in prestressed concrete members. Strain 2011;47:376-386.

3 [8] Martí-Vargas JR, Caro LA, Serna P. Experimental technique for measuring the long-term

4 transfer length in prestressed concrete. Strain 2012;DOI:10.1111/str.12019.

5 [9] Calavera J. Proyecto y cálculo de estructuras de hormigón. Madrid: INTEMAC; 1999.

6 [10] Nilson AH. Design of prestressed concrete. 2nd ed. New York: John Wiley \& Sons; 71987.

8 [11] Al-Omaishi N, Tadros MK, Seguirant SJ. Estimating prestress loss in pretensioned, high9 strength concrete members. PCI J 2009;54(4):132-159.

10 [12] Hale WM, Russell BW. Effect of allowable compressive stress at release on prestress 11 losses and on the performance of precast, prestressed concrete bridge girders. PCI J $12 \quad 2006 ; 51(2): 14-25$.

13 [13] Gutiérrez SE, Cudmani RO, Danesi RF. Time-dependent analysis of reinforced and prestressed concrete members. ACI Struct J 1996;93(4):1-8.

[14] Gilberston CG, Ahlborn TM. A probabilistic comparison of prestress loss methods in 16 prestressed concrete beams. PCI J 2004;49(5):52-69.

[15] Rao KB, Anoop MB, Sreeshylam P, Sridhar S, Kesavan K, Ravisankar K. Assessment of pre-stress losses in instrumented pre-stressed concrete beams using stochastic analysis. Strain 2011;47:175-188.

[16] Francis TK, Au XT. Accurate time-dependent analysis of concrete bridges considering 21 concrete creep, concrete shrinkage and cable relaxation. Eng Struct 2011;33:118-126.

22 [17] Bazant ZP. Prediction of concrete creep effects using age-adjusted effective modulus method. ACI J 1972;69:212-217.

24 [18] FIB. Model Code 2010. First complete draft - Volume 1. Fib Bulletin nº55. Lausanne: 25 International Federation for Structural Concrete; 2010. 
1 [19] PCI. Design Handbook. 7th ed. Chicago, IL: Precast/Prestressed Concrete Institute; 22010.

3 [20] Zia P, Preston HK, Scott NL, Workman EB. Estimating prestress losses. Concr Int $4 \quad 1979 ; 1(6): 32-38$.

5 [21] PCI Commitee on Prestress Losses. Recommendations for estimating prestress losses. $6 \quad$ PCI 1975;20(4):43-75.

7 [22] AASHTO. AASHTO LRFD Bridge Design Specifications. 5th ed.-2012 Interim 8 Revisions. Washington, DC: American Association of State Highway and Transportation 9 Officials; 2012.

10 [23] AASHTO. AASHTO Standard Specifications for Highways Bridges. 17th ed. 11 Washington, DC: American Association of State Highway and Transportation Officials; 2002. 12 [24] AASHTO. AASHTO LRFD Bridge Design Specifications. 3rd ed. Washington, DC: 13 American Association of State Highway and Transportation Officials; 2004.

14 [25] PCI. Bridge Design Manual. 3rd ed. Chicago, IL: Precast/Prestressed Concrete Institute; 152011.

16 [26] Ministerio de Fomento. Instrucción de hormigón estructural (EHE-08). Madrid: 17 Ministerio de Fomento; 2008.

18 [27] CEN. Eurocode 2: Design of concrete structures - Part 1-1: General rules and rules for 19 buildings. European standard EN 1992-1-1:2004:E. Brussels: Comité Européen de 20 Normalisation; 2004.

21 [28] Martí-Vargas JR, Serna-Ros P, Fernández-Prada MA, Miguel-Sosa PF, Arbeláez CA. 22 Test method for determination of the transmission and anchorage lengths in prestressed 23 reinforcement. Mag Concr Res 2006;58(1):21-29. 
1 [29] Martí-Vargas JR, Arbeláez CA, Serna-Ros P, Fernández-Prada, MA, Miguel-Sosa PF.

2 Transfer and development lengths of concentrically prestressed concrete. PCI J $3 \quad 2006: 51(5): 74-85$.

4 [30] Martí-Vargas JR, Serna-Ros P, Arbeláez CA, Rigueira-Victor JW. Bond behaviour of 5 self-compacting concrete in transmission and anchorage. Mater Constr 2006;56(284):27-42.

6 [31] Martí-Vargas JR, Arbeláez CA, Serna-Ros P, Castro-Bugallo C. Reliability of transfer 7 length estimation from strand end slip. ACI Struct J 2007;104(4):487-494.

8 [32] Martí-Vargas JR, Serna P, Navarro-Gregori J, Bonet JL. Effects of concrete composition 9 on transmission length of prestressing strands. Constr Build Mater 2012;27:350-356.

10 [33] Caro LA, Martí-Vargas JR, Serna P. Time-dependent evolution of strand transfer length 11 in pretensioned prestressed concrete members. Mech Time-Depend Mater 12 2012;DOI:10.1007/s11043-012-9200-2.

13 [34] Thorsen N. Use of large tendons in pretensioned concrete. ACI J 1956;2:649-659.

14 [35] CEN. Cement. Part 1: Compositions, specifications and conformity criteria for common cements. European standard EN 197-1:2000. Brussels: Comité Européen de Normalisation; 2000.

[36] AENOR. UNE 36094:1997 Alambres y cordones de acero para armaduras de hormigón pretensado. Madrid: Asociación Española de Normalización y Certificación; 1997. Analytical model for transfer length prediction of $13 \mathrm{~mm}$ prestressing strand. Struct Eng 21 Mech 2007;26:211-229.

22 [38] Martí-Vargas J.R, Serna P., Navarro-Gregori J., Pallarés, L.: Bond of $13 \mathrm{~mm}$ prestressing steel strands in pretensioned concrete members. Eng Struct 2012;41:403-412. 